\title{
ANALYSIS OF PERFORMANCE, COMBUSTION AND EMISSION CHARACTERISTICS ON BIOFUEL OF NOVEL PINE OIL
}

\author{
S. Nallusamy ${ }^{1}$, , S. Sendilvelan ${ }^{1}$, K. Bhaskar ${ }^{2}$ and N. Manikanda Prabu ${ }^{3}$ \\ ${ }^{1}$ Department of Mechanical Engineering, Dr. M G R Educational and Research Institute, \\ Chennai-600095, Tamilnadu, India \\ ${ }^{2}$ Department of Automobile Engineering, Rajalakshmi Engineering College, Thandalam, \\ Chennai-602105, Tamilnadu, India \\ ${ }^{3}$ Department of Mechanical Engineering, Nehru Institute of Engineering and Technology, \\ Coimbatore - 641105, Tamilnadu, India \\ *E-mail: ksnallu@gmail.com
}

\begin{abstract}
Increasing fuel prices lead to developing an alternative renewable fuel for internal combustion engines. Pine oil possesses lower viscosity, boiling point and flash point, similar to other plant based fuels like ethanol and eucalyptus oil. Pine oil has been identified to contain terpineol, a higher alcohol, along with pinene, which is an alicyclic hydrocarbon. In this research work, the various performance and emission characteristics of a single cylinder direct injection diesel engine were studied by using an alternative fuel of the biofuel mixed with pine oil and its blends. The results were compared with standard diesel fuel. From the results, it was found that there is a slight increase in brake thermal efficiency and a decrease in brake specific fuel consumption in all pine blended fuels when compared with regular diesel fuel. The use of pine oil resulted in lower emissions of carbon monoxide, hydrocarbons and increased emissions of nitrogen oxides.
\end{abstract}

Keywords: Performance, Biofuel, Pine oil, Diesel Engine, Carbon Monoxide (CO), Hydrocarbons (HC)

(c) RASĀYAN. All rights reserved

\section{INTRODUCTION}

Nowadays the global is facing an alarming energy crisis, as the available energy resources have started depleting with the rapid rise in population and industrial growth. ${ }^{1}$ Characteristically, the per capita energy consumption of Asia specific region is reportedly higher and this has imposed a threat on the availability of conventional energy sources such as crude oil and coal. Particularly, the crude oil reserves are drastically deprived due to rise in its consumption ${ }^{2}$ and this has resulted in a decline in country's selfsufficiency and energy security. Therefore, every nation continues to import large quantities of crude oil and inadvertently, the import of oil from the leading foreign nations have an adverse effect on the overall availability of crude oil., . $^{3,4}$ Promising alternate fuel for a diesel engine, the experimental analysis of assorted swap and renewable resources of fuel has clutched the interest and concentration of many research scholars by thinking about the future energy protection, sustainability and ecological damage. ${ }^{5,6}$ As such biofuels are being considered as potential alternate fuels for diesel engine applications over the past few decades. ${ }^{7,8}$ Generally, biofuel is the name given to the type of fuel derived from plant based sources and biomass, and are believed to gratify the demands of petroleum fuels in the near future. ${ }^{9-11}$ The presence of inherent oxygen in these biofuels, unlike conventional fuels, offers immense benefits in respect of engine combustion, performance, and emission. Biofuels, in addition to being renewable and biodegradable, have considerably reduced the level of exhaust gases like hydrocarbons, carbon monoxide and smoke emissions ${ }^{12}$, when being used in a diesel engine. Most significantly, $\mathrm{CO}_{2}$ emission, the greenhouse gas, which causes global warming, has been reported to be reduced. ${ }^{13}$ Information on blend properties, engine performance, durability and emissions on diesel-ethanol blends were studied and 
reported. ${ }^{14}$ In an investigation on alcohols as fuels for IC engines the production of ethanol and its properties, along with the performance and emission characteristics for diesel-ethanol blends were reported. ${ }^{15}$ Interestingly, the review work underscored the need for material compatibility studies with diesel-alcohol blends. The impacts of ethanol and n-butanol blends on regulated as well as non-regulated emissions from a diesel engine, during transient operating conditions were reviewed. ${ }^{16,}{ }^{17}$ In the same year, Kumar et al considered three different alcohol-diesel blends such as diesel-methanol, diesel-ethanol, and diesel-butanol and brought some critical information about the fuel properties, the economics of production and their effect on engine performance and emission. ${ }^{18}$ Pine oil-diesel blends in a single cylinder, direct injection diesel engine was studied. The results showed that fueling with $100 \%$ pine oil under the full load condition decreased the $\mathrm{CO}, \mathrm{HC}$, and smoke emissions, whereas the nitrogen oxides (NOx) emission increased. ${ }^{19,22}$ Combustion and emission characteristics of a cylinder diesel engine fueled with pine oil-biodiesel blends were experimentally tested. Experimental results showed that the 50\% pine oil-50\% biodiesel blend had the optimum performance. Under the full load condition, the CO, HC, and smoke emissions were lower than diesel, respectively, and the NOx emission was comparable to that of diesel. ${ }^{20-22}$ The emission characteristics of pine oil blend in a diesel engine equipped with SCR and catalytic converter were investigated. ${ }^{22,23}$ The brake thermal efficiency increased with the increase in the blending ratio of pine oil. The $\mathrm{CO}, \mathrm{HC}$, smoke, and NOx emissions decreased. The above-mentioned discussion clearly shows pine oil to be a promising alternative fuel for diesel engines. From the above discussion, it is certain that more research on the exploration of different biofuels for diesel engine application has been incepted in the past. ${ }^{22}$ For instance, in a country like India, to meet the requirement of 200 billion gallons of fuel the prominent biodiesel-Jatropha would alone be not sufficient ${ }^{24,} 25$. Therefore, innovation of many novel biofuels would help deal with the availability and also enable every nation to attain self-sufficiency, besides protecting the environment from harmful emissions. Based on the above literature, an attempt was made with to find the performance, combustion and emission characteristics of a single cylinder, constant speed and direct injection diesel engine using pine oil and its blends as an alternative fuel to reduce the emission and increase the brake thermal efficiency.

\section{Pine oil biofuel-An overview}

\section{EXPERIMENTAL}

Pine oil biofuel, a renewable biomass based source of fuel is distinctive in that the feedstock originates from the forest and can be blended with petroleum-based diesel fuel. In general, the pine tree is widely grown for its bark, wood, tar and essential oil which can grow up to 40 meters. The essential oil obtained from pine tree is called pine oil, which is pale yellow in color and has a fresh forest smell. The estimated global level of production was reported about 30,000 tons per annum of pine oil and the demand for it by the year of 2022 was forecasted about 8,53,900 tons. Typically, there are three different varieties of pine oil known as gum, wood and sulfate pine oil, each being produced from different parts of a pine tree and has their own distinctions. ${ }^{26}$ Among the three categories, the gum pine oil is of much significance and the raw material used for the synthesis of it is called Pine oleoresin. It seems that a pine tree can supply an average of $2.75 \mathrm{~kg}$ of pine oleoresin contains about $20 \%$ of turpentine and $65 \%$ of rosin and turpentine present in it is then further processed to produce pine oil. ${ }^{27}$

\section{Production of pine oil}

The raw material for producing pine oil is oleoresin collected separately from the pine tree by drumming procedure. To begin with, the oleoresins are first washed and placed in a reactor, surrounded by cylindrical coils, which facilitates the supply of hot steam. After the passage of steam, oleoresins are separated into rosin and turpentine vapors, the latter is then sent into a condenser and liquid turpentine collected. The turpentine by itself is bio oil, containing low boiling fraction compounds such as $\alpha$-pinene and B-pinene as its major constituents. After the separation of the low boiling fraction compounds from the oleoresins, rosin is left behind as a residue, which has the characteristics of camphor. To synthesize pine oil, turpentine is allowed to react with ortho-phosphoric acid and at the end of the reaction; pine oil is collected as an essential oil and the prepared pine oil with diesel blend is shown in Fig.-1. 


\section{Composition of pine oil}

The constituents of pine oil are identified pinene $\left(\mathrm{C}_{10} \mathrm{H}_{16}\right)$ and terpineol $\left(\mathrm{C}_{10} \mathrm{H}_{18} \mathrm{O}\right)$ as its major constituents. However, unlike methanol and ethanol, the alcohol group present in pine oil was noted to be terpineol, a tertiary alcohol, and the presence of pinene in it makes some distinctions to its quality. However, related to less alcohol content like ethanol and methanol, terpineol has carbon, hydrogen and oxygen atoms in its construction, budding as a renewable source of regular fuel in the realms of other alternating fuels. Chemically speaking, pine oil is an alicyclic hydrocarbon and from its molecular structure, it is evident that it has lower molecular weight and shorter carbon chain length than that of diesel or biodiesel. The various thermal properties of pine oil biofuel are given in Table-1.

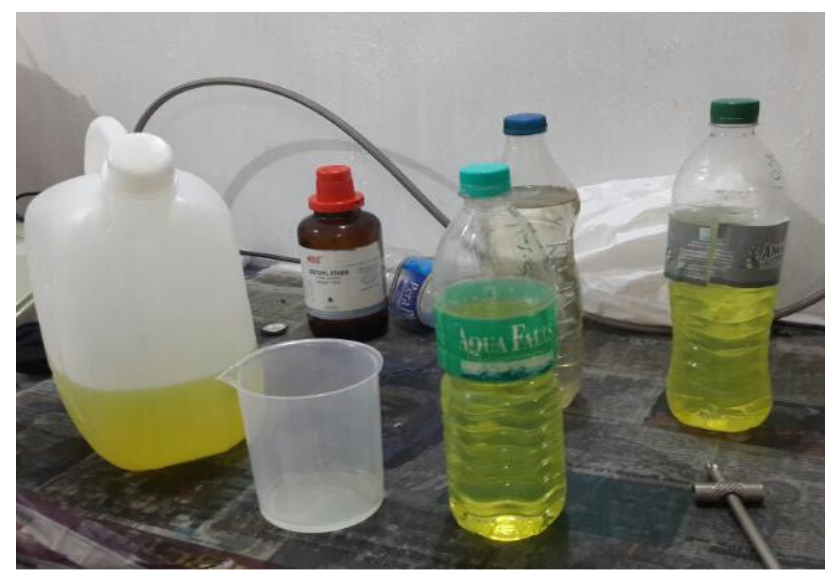

Fig.-1: Pine oil-Diesel Blend

The engine used for the experimentation is a stationary diesel engine of Kirloskarmakes, running at a constant speed of 1500rpm as shown in Fig.-2. This engine, which is typically a generator set, is said to be used for marine, agricultural and other industrial applications and is deemed to produce a maximum power output of $5.2 \mathrm{~kW}$. Characteristically, this naturally aspirated diesel engine possesses a cylinder, cylinder head, piston, bowl in piston combustion chamber and other typical elements. The various properties of pine oil biofuel such as flash point, fire point, viscosity, etc are given in Table-1. Similarly, the characteristic dimension of the bore, stroke and other specifications of the engine are given in Table-2.

Table-1: Properties of Pine Oil Biofuel

\begin{tabular}{l|l}
\hline \multicolumn{1}{c|}{ Property } & \multicolumn{1}{c}{ Pine Oil } \\
\hline Flash point & $54^{\circ} \mathrm{C}$ \\
\hline Fire point & $65^{\circ} \mathrm{C}$ \\
\hline Viscosity at $40^{\circ} \mathrm{C}$ & $3.07 \mathrm{cSt}$ \\
\hline Calorific value $(\mathrm{CV})$ & $41500 \mathrm{KJ} / \mathrm{Kg}$ \\
\hline Density & $857.6 \mathrm{Kg} / \mathrm{m}^{3}$ \\
\hline Cetane number & 38.9 \\
\hline
\end{tabular}

\section{In-cylinder pressure measurement}

By means of AVL combustion analyzer with AVL 619, the pressure of in-cylinder and cyclic variations were recorded. The combustion analyzer fundamentally has an analog to digital converter with 16 channels enabling external and internal triggering option, charge amplifier and PC interface. The sample of exhaust was passed through moisture separator and filter element to prevent water vapor and 
particulates from entering into the analyzer. Typically, $\mathrm{HC}$ and NOX were measured in parts per million (ppm) and $\mathrm{CO}, \mathrm{CO} 2$ and $\mathrm{O} 2$ emissions were measured in terms of percentage volume. Smoke level was measured in hartridge smoke unit (HSU) using a standard AVL $437 \mathrm{C}$ smoke meter. The smoke was measured based on the principle of light extermination wherein, the net amount of light blocked was measured in terms of smoke cloudiness.

Table-2: Engine Specifications

\begin{tabular}{l|c}
\hline \multicolumn{1}{c|}{ Model } & Specification \\
\hline No. of cylinder & 1 \\
\hline Cylinder Bore (mm) & 87.50 \\
\hline Power (kW) & 5.20 \\
\hline Speed (RPM) & 1500 \\
\hline Stroke Length (mm) & 110.00 \\
\hline Connecting rod length (mm) & 234.00 \\
\hline Compression ratio & 17.50 \\
\hline Swept volume (cc) & 661.45 \\
\hline
\end{tabular}

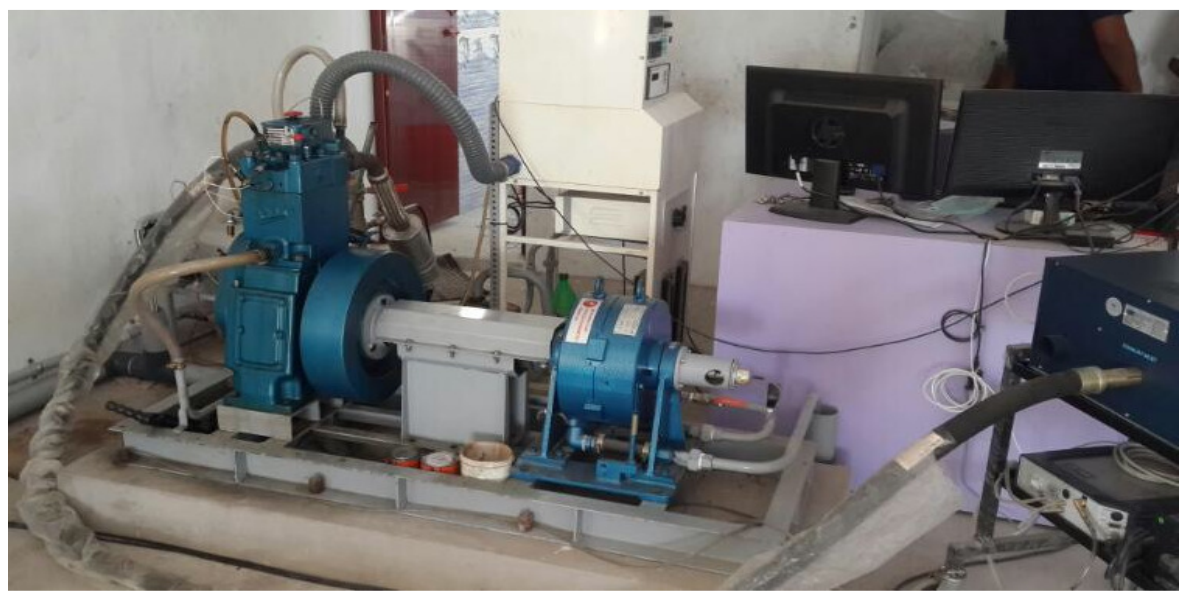

Fig.-2: Experimental Test Rig

Based on the comprehensive literature review on the feasibility of using less viscous fuels in a diesel engine, pine oil was construed to be used in three different modes such as blend, dual and neat fuel mode. Different blends of pine oil with diesel such as $5 \%$ pine, $10 \%$ pine, $20 \%$ pine and $30 \%$ pine were prepared by stirring the mixtures in an ultrasonic agitator so as to keep the blend integrity. Finally, the prepared blends were experimentally investigated in a single cylinder diesel engine without any engine modifications. The various characteristics presented in this article were experimentally analyzed with constant speed for the different power output of the engine.

\section{RESULTS AND DISCUSSION}

Figure-3 shows the variation of specific energy consumption with a load for diesel at $5 \%, 10 \%, 20 \%$ and $30 \%$ pine oil. At full load, the fuel consumption of various percentages tested varies from $1.27 \mathrm{~kg} / \mathrm{hr}$ to $1.32 \mathrm{~kg} / \mathrm{hr}$ and the brake thermal efficiency varies from $34 \%$ to $37 \%$. Lower kinematic viscosities of pine blends with 3.07 centistokes (cSt) compared to that of diesel with $3.5 \mathrm{cSt}$ result in good atomization, vaporization and dispersion of fuel in the combustion chamber. The lower calorific value of pine blends $(41,500 \mathrm{~kJ} / \mathrm{kg})$ compared to diesel $(43,500 \mathrm{~kJ} / \mathrm{kg})$ result in higher fuel consumption of blends compared to diesel at all the power outputs resulting in higher SEC and lower brake thermal efficiency. From the 
RASĀYAN J. Chem.

Vol. 10 | No. 3 |873 - 880 | July - September | 2017

readings, it was observed that the fuel consumption for all the fuel blends tested increases with increase in load.

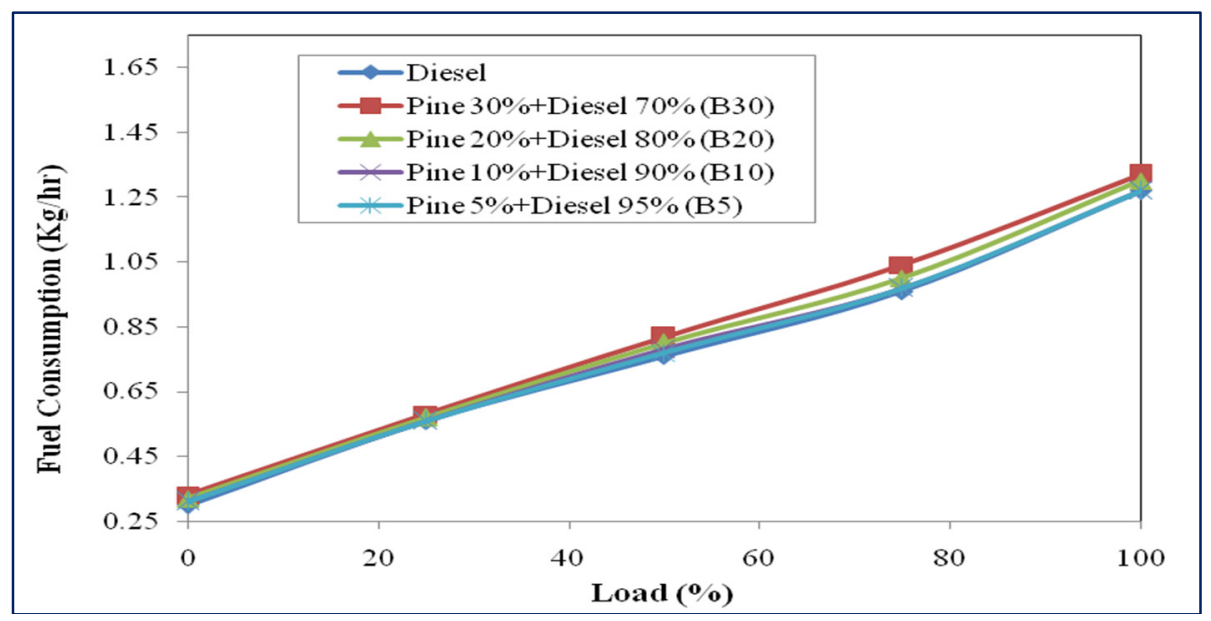

Fig.-3: Difference of Fuel Consumption Vs Load

Figure-4 shows the variation of brake thermal efficiency with applied load for pine oil and its blends in comparison with diesel. The brake thermal efficiency indicates that, how the heat energy is effectively converted into work energy and also indicate combustion of fuel. As a result, the brake thermal efficiency increases with increase in applied load. From Fig.-4 it can be seen that the addition of pine oil proportionately with diesel slightly decreases the overall efficiency of the diesel engine. The variations of brake thermal efficiency for the blend fuels were nearly comparable to that of diesel fuel.

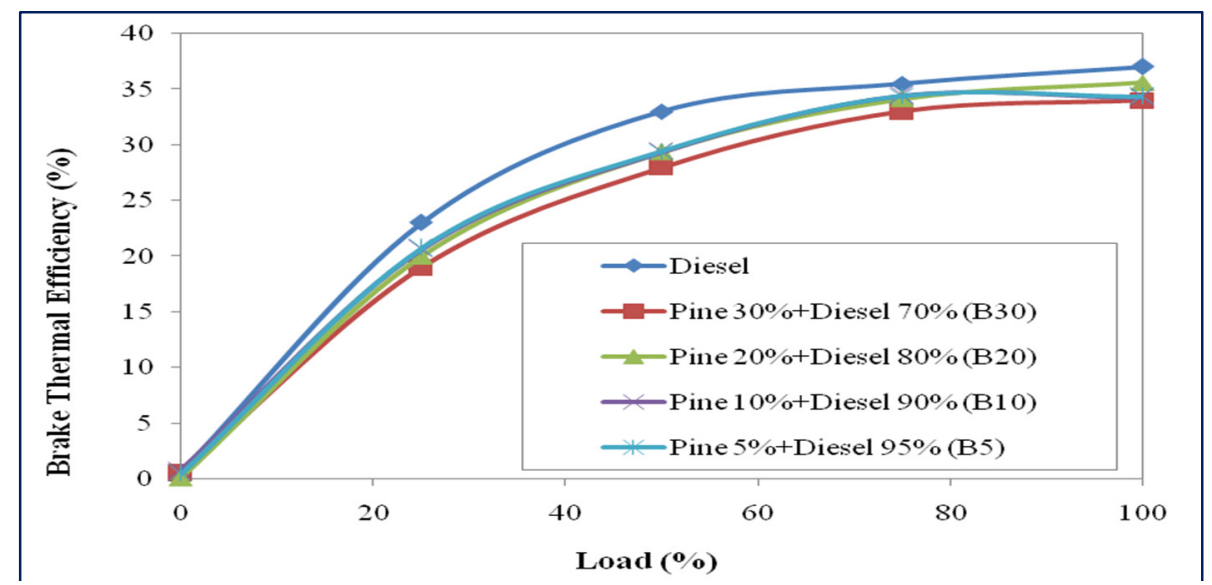

Fig.-4: Difference of Brake Thermal Efficiency Vs Load

Figure- 5 shows the $\mathrm{CO}$ emissions of the pine oil diesel blends. $\mathrm{CO}$ is an intermediate combustion product which is formed by incomplete combustion of fuel. At all loads, it was observed that there is a decrease in the level of $\mathrm{CO}$ emission for pine oil blends and also the level of $\mathrm{CO}$ emission reduces with the increase in the percentage of pine oil. This is due to the oxygen content present in the pine oil which increases the combustion rate. On the other hand, at the lower loading conditions regular diesel generates a lesser amount of CO compared with blends pine oil, because when the diesel engine is working at $20 \%$ of loading conditions, the air fuel ratio is very minimum and the supply of oxygen can further reduce and leads to affect the combustion process, there by advanced $\mathrm{CO}$ emissions released by pine oil with its blends. 
Figure- 6 shows the impact of pine oil blend over the emission of HC. The increased evaporation rate of fuel with air inside the cylinder makes the fuel burn completely. Also found that the addition of load, the emission of $\mathrm{HC}$ enhances ask the total volume of the fuel supplied to the engine cylinder is higher and the air fuel ratio is also improved for pine oil biofuel. It is seen that pine oil blends give a lower amount of $\mathrm{HC}$ emission compared to that of diesel at all load conditions. This is due to the availability of relatively low oxygen content inside the cylinder for the combustion.

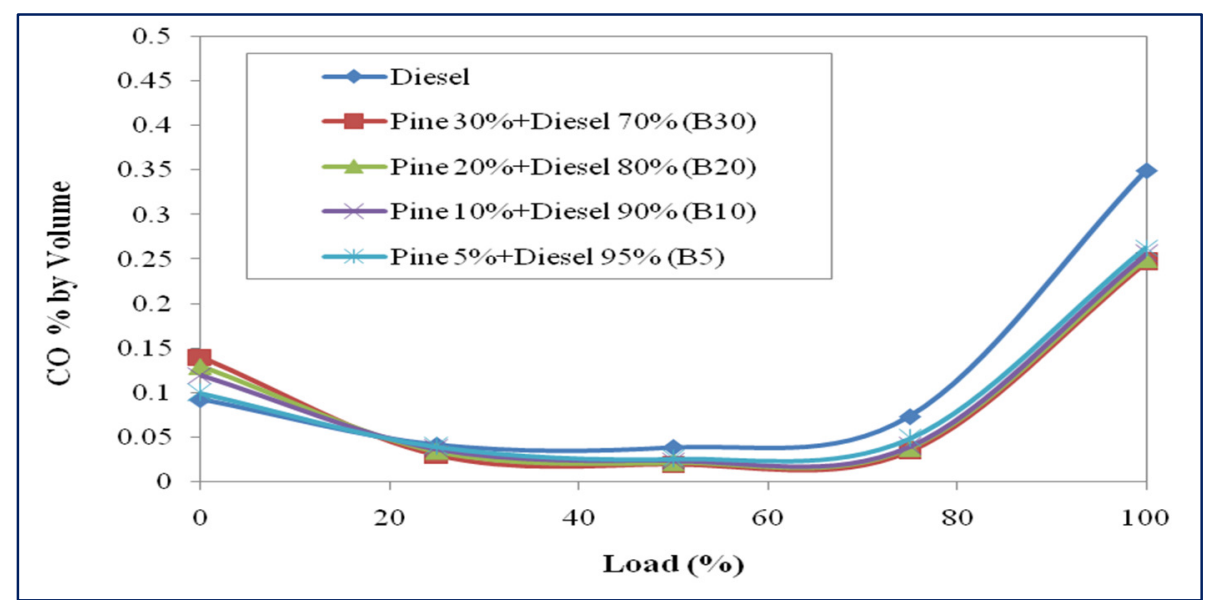

Fig.-5: Difference of Carbon monoxide Vs Load

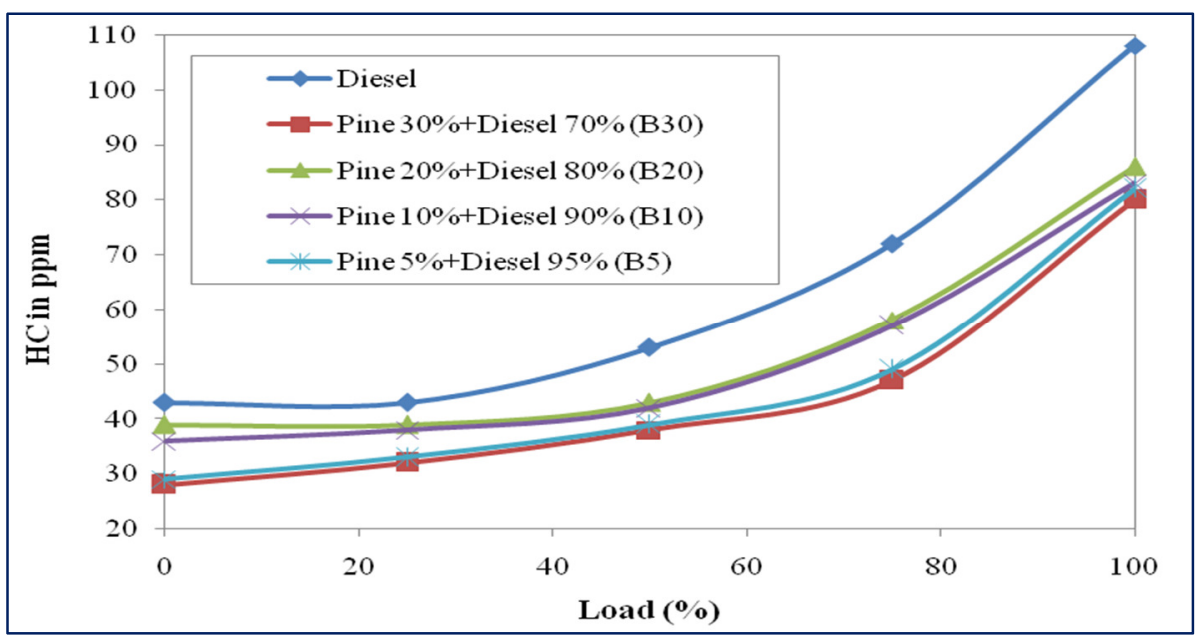

Fig.-6: Difference of Hydrocarbon Vs Load

NOx is the most important emissions for diesel engine due to increase in temperature and combustion diffusion in the combustion chamber. The variations are shown in Figure-7. A higher level NOx emission was observed during the direct injection engine was operated at high loading conditions with pine oil blends. This is because of increased temperature which is caused by enhanced premixed burning. Due to the extended ignition delay during the burning of pine oil with its blends, there is an accretion of the airfuel mixture in the engine combustion chamber. From the result, it was found that the NOx emission level is higher in $30 \%$ of pine oil blends compared to the regular diesel, since the operating temperature is directly proportional to NOx. On the other hand, at lower loading conditions the higher level of NOx is formed in the regular diesel hence it has relatively superior fuel to air ratio and it dominates the combustion process at the maximum lesser load settings. 
Figure-8 portrays the opacity characteristics of blends of pine oil mixed with diesel for various loads of the internal combustion engine. The development of smoke is accredited to either mixture of air fuel which is too lean or too rich to auto ignite. The oxygen presented in the pine oil can assist for the complete combustion process. The result reveals that in the pine oil methyl ester there is a rich amount of emission because of there is an enhancement in the particulates with the fuel. Finally, a lower level of the smoke level could be observed for $5 \%$ of pine oil with diesel. In all the loading conditions about $30 \%$ of pine proves increased smoke emission and particularly there is a considerable increase the level of smoke at high loading condition.

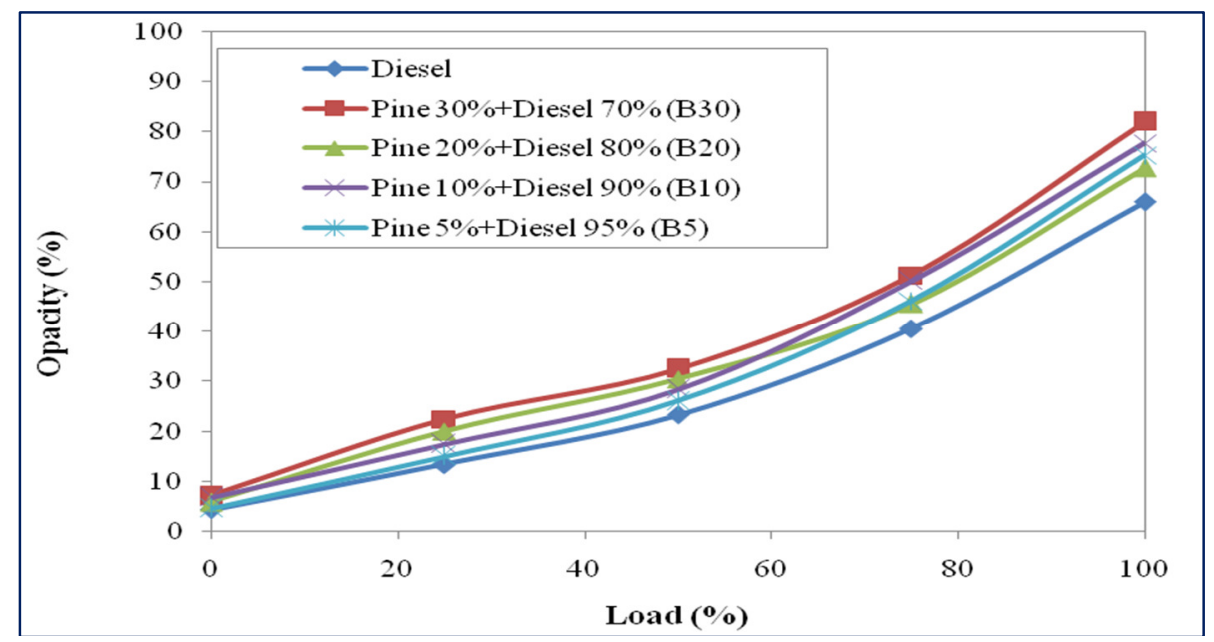

Fig.-7: Difference of Nitrogen Oxides Vs Load

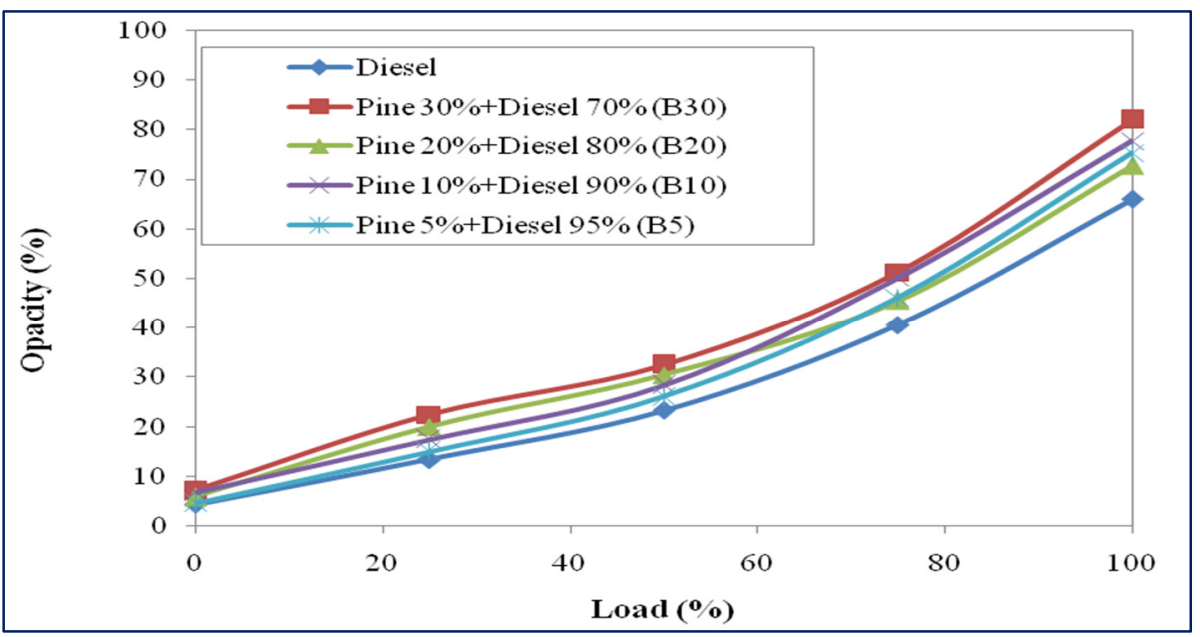

Fig. -8: Difference of Opacity Vs Load

CONCLUSION

The experiment was carried out with different parameters Vs various loading conditions. The investigation results pointed out that, the pine oil can be directly used in a diesel engine without transesterification as a result of its unique chemical possessions. Based on the experimental results the following conclusions were made.

- $5 \%$ of pine oil showed significantly comparable thermal efficiency and consumption of specific fuel with diesel, which is noteworthy as a biodiesel while alcohol fuels suffer a setback of higher fuel consumption. 
- According to the emission reports, the $\mathrm{HC}$ and $\mathrm{CO}$ emissions level have been considerably reduced for pine oil compared with regular diesel at advanced loading conditions. On the other hand, pine oil shows an advanced level of NOX emission compared with normal diesel.

- As a result, it was concluded that $\mathrm{HC}$ and $\mathrm{CO}$ emission reduction is possible when the outlay of advanced NOX attained from the pine oil biofuel used in a constant speed single cylinder diesel engine without any alterations.

\section{REFERENCES}

1. R. Vallinayagam, S. Vedharaj, W.M. Yang, W.L. Roberts and R.W. Dibble, Renewable and Sustainable Energy Reviews, 51, 1166(2015)

2. S. Nallusamy, Pollution Research, 34(4), 721(2015)

3. Harikrishnan and R. Sabarish, Middle-East Journal of Scientific Research, 20(6), 709(2014)

4. S. Nallusamy, N. Manikanda Prabu, International Journal of Nanoscience, 16(3), 01(2017)

5. R. Vallinayagam, S. Vedharaj, W.M. Yang, P.S. Lee, K.J.E. Chua and S.K. Chou, Energy, 57, 344(2013)

6. S. Nallusamy and Gautam Majumdar, International Journal of Performability Engineering, 12(3), 229(2016)

7. Gaurav Sharma, Devendra Dandotiya and S.K. Agrawal, International Journal of Modern Engineering Research, 23, 172(2014)

8. S. Nallusamy, A. Manoj Babu and N. Manikanda Prabu, International Journal Applied Engineering Research, 10(62), 112(2015)

9. S. Sendilvelan and K. Bhaskar, Rasayan Journal of Chemistry, 10(1), 111(2017)

10. S. Nallusamy and A. Manoj Babu, Journal of Nano Research, 37, 58(2015)

11. A. Karthikeyan and S. Nallusamy, International Journal of Engineering Research in Africa, 31, 36(2017)

12. S. Sendilvelan, K. Rajan, Rasayan Journal of Chemistry, 10(1), 190(2017)

13. H. Reddy and N.Balajiganesh, Undergraduate Academic Res. Journal,01(2), 2278(2012)

14. S. Sendilvelan, K. Jeyachandran and K. Bhaskar, American Society of Mechanical Engineers, Internal Combustion Engine Division, 36, (2001)

15. S. Nallusamy, International Journal of Engineering Research in Africa, 23, 174(2016)

16. S. Nallusamy, International Journal of Performability Engineering, 12(2), 143(2016)

17. S. Nallusamy, Journal of Nano Research, 45, 155(2017)

18. T.C. Watling, M.R. Ravenscroft and G. Avery, In Catalysis Today, 188, 32(2012)

19. S. Nallusamy, Journal of Nano Research, 40, 105(2016)

20. S. Sendilvelan, K. Bhaskar, Rasayan Journal of Chemistry, 9(4), 692(2016)

21. S. Sendilvelan, K. Bhaskar and S. Nallusamy, Rasayan Journal of Chemistry, 10(2), 454 (2017)

22. Huang, Haozhong, Wenwen Teng, Qingsheng Liu, Chengzhong Zhou, Qingxin Wang and Xueqiang Wang, Energy Conversion and Management, 128, 317(2016)

23. E.M. Shahid and Y. Jamal, Pakistan Journal of Engg. and Applied Science,9, 68(2011)

24. N. Manikanda Prabu, T.Senthil Kumar and S. Nallusamy, Applied Mechanics and Materials, 592594, 1520(2014)

25. S. Nallusamy, Journal of Nano Research, 40, 105(2016)

26. Meenakshi and Sudhan, Chemical Science Transactions, 4(1), 127(2015)

27. S. Nallusamy and Saurabh Kumar, Indian Journal of Science and Technology, 9(16), 01(2016)

[RJC-1787/2017] 